\title{
Pulmonary vasoconstrictor action of KCNQ potassium channel blockers Shreena Joshi ${ }^{1,2}$, Prabhu Balan ${ }^{1}$ and Alison M Gurney*1,2
}

Address: ${ }^{1}$ Department of Physiology \& Pharmacology, University of Strathclyde, 27 Taylor street, Glasgow G4 0NR, UK and ${ }^{2}$ Faculty of Life Sciences, University of Manchester, Floor 2, Core Technology Facility, University of Manchester, 46 Grafton Street, Manchester M13 9NT, UK

Email: Shreena Joshi - Shreena.Joshi@postgrad.manchester.ac.uk; Prabhu Balan - prabhu.balan@strath.ac.uk; Alison M Gurney* - alison.gurney@manchester.ac.uk

* Corresponding author

Published: 20 February 2006

Respiratory Research 2006, 7:31 doi:10.1186/1465-9921-7-31
Received: 0I November 2005

Accepted: 20 February 2006

This article is available from: http://respiratory-research.com/content/7/I/31

(c) 2006 Joshi et al; licensee BioMed Central Ltd.

This is an Open Access article distributed under the terms of the Creative Commons Attribution License (http://creativecommons.org/licenses/by/2.0), which permits unrestricted use, distribution, and reproduction in any medium, provided the original work is properly cited.

\begin{abstract}
Background: KCNQ channels have been widely studied in the nervous system, heart and inner ear, where they have important physiological functions. Recent reports indicate that KCNQ channels may also be expressed in portal vein where they are suggested to influence spontaneous contractile activity. The biophysical properties of $\mathrm{K}^{+}$currents mediated by $\mathrm{KCNQ}$ channels resemble a current underlying the resting $\mathrm{K}^{+}$conductance and resting potential of pulmonary artery smooth muscle cells. We therefore investigated a possible role of KCNQ channels in regulating the function of pulmonary arteries by determining the ability of the selective KCNQ channel blockers, linopirdine and XE99I, to promote pulmonary vasoconstriction.
\end{abstract}

Methods: The tension developed by rat and mouse intrapulmonary or mesenteric arteries was measured using small vessel myography. Contractile responses to linopirdine and XE99I were measured in intact and endothelium denuded vessels. Experiments were also carried out under conditions that prevent the contractile effects of nerve released noradrenaline or ATP, or block various $\mathrm{Ca}^{2+}$ influx pathways, in order to investigate the mechanisms underlying contraction.

Results: Linopirdine and XE99/ both contracted rat and mouse pulmonary arteries but had little effect on mesenteric arteries. In each case the maximum contraction was almost as large as the response to $50 \mathrm{mM} \mathrm{K}^{+}$. Linopirdine had an $\mathrm{EC}_{50}$ of around I $\mu \mathrm{M}$ and XE99I was almost 10 -fold more potent. Neither removal of the endothelium nor exposure to phentolamine or $\alpha, \beta-$ methylene ATP, to block $\alpha_{1}$-adrenoceptors or P2X receptors, respectively, affected the contraction. Contraction was abolished in $\mathrm{Ca}^{2+}$-free solution and in the presence of $\mathrm{I} \mu \mathrm{M}$ nifedipine or $10 \mu \mathrm{M}$ levcromakalim.

Conclusion: The KCNQ channel blockers are potent and powerful constrictors of pulmonary arteries. This action may be selective for the pulmonary circulation as mesenteric arteries showed little response. The results imply that the drugs act directly on smooth muscle cells and contraction requires voltage-dependent $\mathrm{Ca}^{2+}$ influx. It is concluded that the drugs probably act by blocking $\mathrm{KCNQ}$ channels in pulmonary artery myocytes, leading to membrane depolarization and $\mathrm{Ca}^{2+}$ influx through L-type $\mathrm{Ca}^{2+}$ channels. This implies a functional role for KCNQ channels in regulating the resting membrane potential of pulmonary artery myocytes. 


\section{Background}

KCNQ (Kv7) genes encode a family of voltage-gated $\mathrm{K}^{+}$ channels with 6 membrane spanning domains and a single P-loop that forms the selectivity filter of the pore. Members of this channel family have been widely studied in the nervous system, heart and inner ear, where they have important physiological functions $[1,2]$. In the nervous system, KCNQ channels are thought to underlie the $\mathrm{M}$-current, a non-inactivating, voltage-dependent $\mathrm{K}^{+}$current that plays a critical role in regulating neuronal excitability and action potential firing frequency [3]. It was originally thought that M-current is mediated by heteromultimeric channels formed by KCNQ2 and KCNQ3 subunits [4], but it may also require association with the regulatory, KCNE2 subunit [5]. Moreover, $\mathrm{K}^{+}$currents with characteristics similar to $\mathrm{M}$-current can also be produced by homomultimers of KCNQ1, KCNQ2, KCNQ3, KCNQ4 and KCNQ5 [2], as well as heteromers of KCNQ3 and KCNQ5 [6,7]. Thus there may be significant molecular diversity in the composition of M-like currents in different cell types.

$\mathrm{K}^{+}$currents produced by the heterologous expression of different KCNQ genes in Xenopus oocytes or mammlian cell lines display distinct properties. In general though, they can be activated at rather negative membrane potentials, below $-60 \mathrm{mV}$, are outwardly rectifying and show little or no inactivation [2]. Similar characteristics are displayed by a $\mathrm{K}^{+}$current found in pulmonary artery smooth muscle cells, which plays a key role in regulating the resting membrane potential [8]. Although part of this current has been proposed to be mediated by two-pore domain TASK channels [9], there is a residual component that remains to be identified. Its similarity to the M-current has led us to speculate that it might be mediated by KCNQ channels and that KCNQ channels might therefore play a role in regulating the resting membrane potential of pulmonary artery smooth muscle cells. Consistent with this idea, expression of KCNQ1 and the regulatory subunit, KCNE4, has been reported in lung [10,11]. Although not examined in pulmonary arteries, KCNQ1 transcripts have also been reported in the mouse portal vein [12], where there is evidence that they have a functional role in regulating spontaneous contractile activity [13].

Inhibition of the $\mathrm{K}^{+}$channels contributing to the resting membrane potential of pulmonary artery smooth muscle cells would cause membrane depolarisation. If the cells depolarise sufficiently to reach the threshold for activating L-type $\mathrm{Ca}^{2+}$ channels, the result would be $\mathrm{Ca}^{2+}$ influx and muscle contraction. The ability of inhibitors of KCNQ channels to induce pulmonary artery contraction would therefore provide support for a role of these channels in regulating the resting potential. Due to their selective inhibition of KCNQ channels, the drugs linopirdine and
XE991 (a more potent analogue of linopirdine) have been used as markers of these channels $[1,2]$. Their effect on Mcurrent is thought to be a major factor in the abilities of these drugs to stimulate the release of central neurotransmitters [14], an action that led to these drugs being considered as cognition enhancers and investigated for the treatment of Alzheimer's disease. Linopirdine inhibits native $\mathrm{M}$-currents at low micromolar concentrations and is around 20-fold less potent at inhibiting other voltagegated $\mathrm{K}^{+}$channels [15]. Linopirdine and XE991 inhibit heterologously expressed KCNQ channels with varying potency, depending on their subunit composition, but at concentrations effective at blocking KCNQ channels they are without effect on a number of other recombinant $\mathrm{K}^{+}$ channels $[2,4,16]$.

This study investigated the effects of the KCNQ channel blockers, linopirdine and XE991, on isolated rat and mouse pulmonary arteries, with the aim of determining whether or not KCNQ channels could potentially play a role in regulating the resting membrane potential and tone of pulmonary artery smooth muscle.

\section{Methods}

This investigation was carried out under regulations dictated by the UK Scientific Procedures (Animals) Act 1986 and conforms to the Guide for the Care and Use of Laboratory Animals published by the National Institutes of Health (NIH Publication No. 85-23, revised 1996). Male Sprague Dawley rats (250-300 g) and BALB/c mice (4-5 weeks old) were killed by cervical dislocation. The lungs and mesentery were rapidly excised into physiological salt solution (PSS) containing (mM): $\mathrm{NaCl} 120 ; \mathrm{KCl} 5 ; \mathrm{MgCl} 2$ 1; NaH2PO4 0.5; KH2PO4 0.5; glucose 10; $\mathrm{CaCl}_{2} 1 ; \mathrm{pH}$ 7.4. Intrapulmonary arteries and mesenteric arteries with external diameters of 300-400 $\mu \mathrm{m}$ (rats) or 100-200 $\mu \mathrm{m}$ (mice) were dissected free of connective tissue and mounted in a small vessel myograph (Danish Myotechnology). The vessels were bathed in PSS, continually aerated at $37^{\circ} \mathrm{C}$. A basal tension of $5 \mathrm{mN}$ (rat) or $4 \mathrm{mN}$ (mouse) was applied and vessels allowed to equilibrate for $40 \mathrm{~min}$, washing every $15 \mathrm{~min}$, before beginning the experiment.

At the start of each experiment, vessels were exposed to 50 $\mathrm{mM} \mathrm{K+}$ until a maximal contractile response was observed. This was done by replacing the PSS in the bath with PSS in which the $\mathrm{K}^{+}$concentration was increased to $50 \mathrm{mM}$ by equimolar substitution of $\mathrm{KCl}$ for $\mathrm{NaCl}$. The vessels were then washed until tension returned to baseline and the challenge with high $\mathrm{K}^{+}$was repeated until reproducible contractions were produced. Following washout and recovery of tension to baseline, the tissue was then exposed to increasing concentrations of linopirdine ( $1 \mathrm{nM}$ - $100 \mu \mathrm{M})$ or XE991 $(0.1 \mathrm{nM}-100 \mu \mathrm{M})$, applied in a 
A

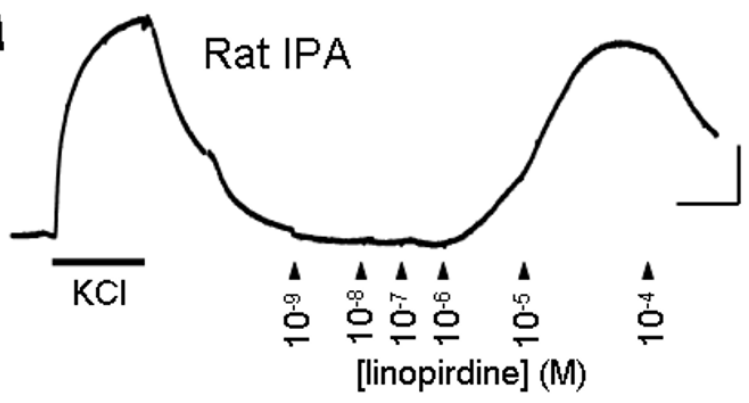

c

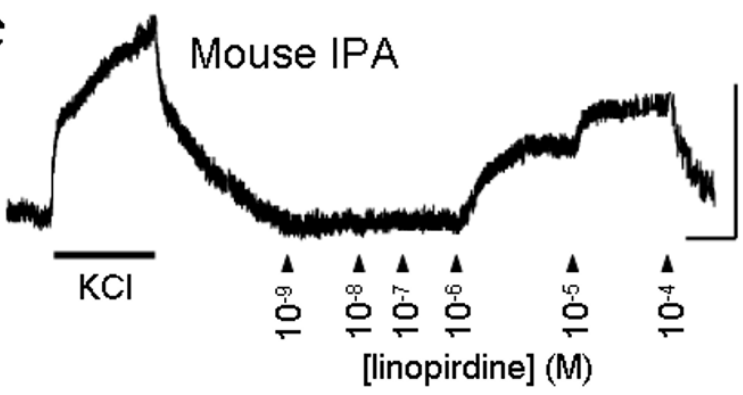

$\boldsymbol{E}$

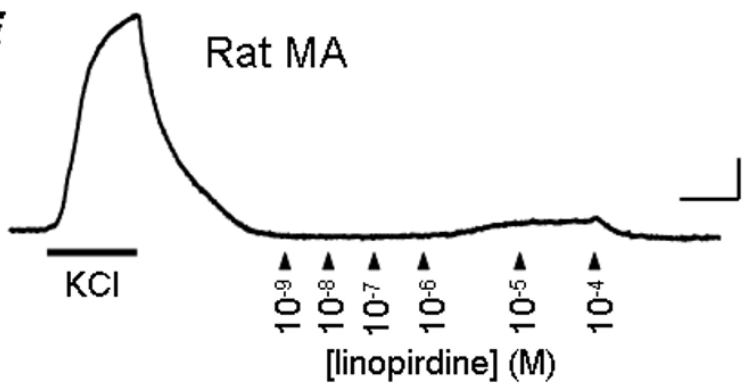

B

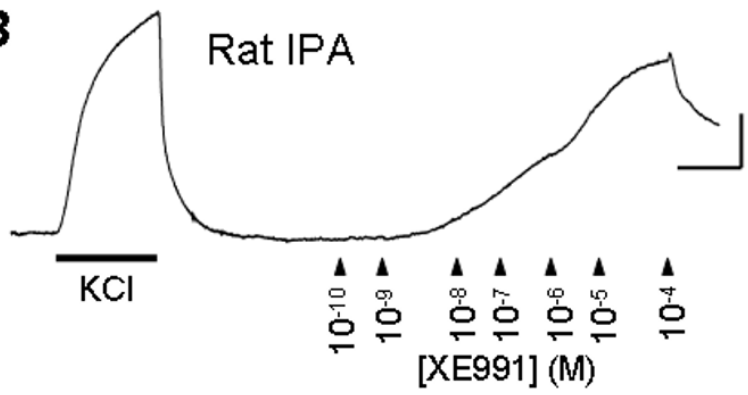

D

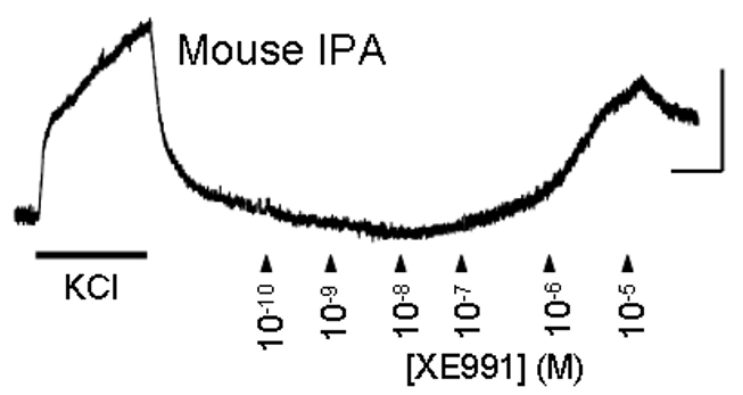

$\boldsymbol{F}$

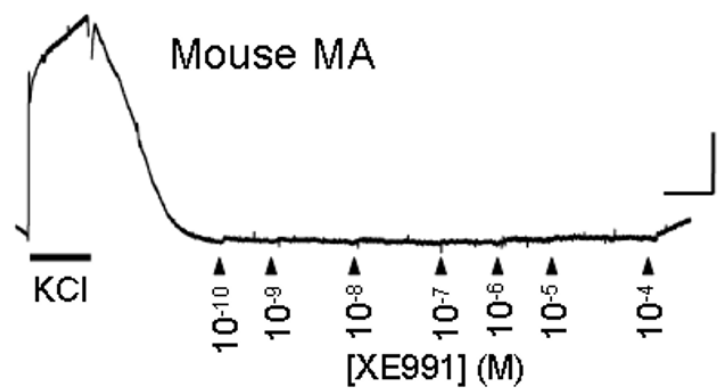

Figure I

KCNQ channel blockers constrict pulmonary, but not mesenteric artery. Original records of tension developed by rat $(A, B)$ and mouse $(C, D)$ intrapulmonary artery (IPA) in the presence of $50 \mathrm{mM} \mathrm{KCl}$ or increasing concentrations of linopirdine or XE991, applied where indicated. Original records of tension developed by rat $(E)$ and mouse $(F)$ mesenteric arteries (MA) show responses to $50 \mathrm{mM} \mathrm{KCl}$, but not linopirdine or XE99I applied at the same concentrations. Calibration bars are I $\mathrm{mN}$ (vertical) and $10 \mathrm{~min}$ (horizontal).

cumulative manner with an interval of at least $10 \mathrm{~min}$ between additions. Contractile responses to these drugs were measured as a percentage of the response to $50 \mathrm{mM}$ $\mathrm{K}^{+}$in each vessel. In some experiments the endothelium was removed by rubbing the lumen of the vessel with a human hair. The failure of acetylcholine $(1 \mu \mathrm{M})$ to relax vessels pre-constricted with $1 \mu \mathrm{M}$ phenylephrine was taken to indicate successful denudation. As relaxant responses were not always abolished by this procedure, experiments on endothelium-denuded vessels were also carried out in the presence of the nitric oxide synthase inhibitor N(G)-nitro-L-arginine methyl ester (L-NAME, $100 \mu \mathrm{M})$ and the cyclooxygenase inhibitor indomethacin $(10 \mu \mathrm{M})$.
Rat intrapulmonary arteries were used to investigate the mechanism of constriction caused by the KCNQ channel blockers. The response to a single application of linopirdine $(10 \mu \mathrm{M})$ or XE991 $(1 \mu \mathrm{M})$ was first established. After washout and recovery to baseline tension, the tissue was then bathed for 20 min in $\mathrm{Ca}^{2+}$-free bath solution, which was identical to PSS but with $\mathrm{CaCl}_{2}$ omitted and $1 \mathrm{mM}$ EGTA added. The vessels were then challenged again with linopirdine or XE991. To control for time-dependent changes in the response amplitude, in some experiments linopirdine or XE991 was first applied in $\mathrm{Ca}^{2+}$-free bath solution and the application repeated after returning to normal PSS. The effects of nifedipine $(1 \mu \mathrm{M})$, levcromaka$\lim (10 \mu \mathrm{M})$ and phentolamine $(10 \mu \mathrm{M})$ on contractile 

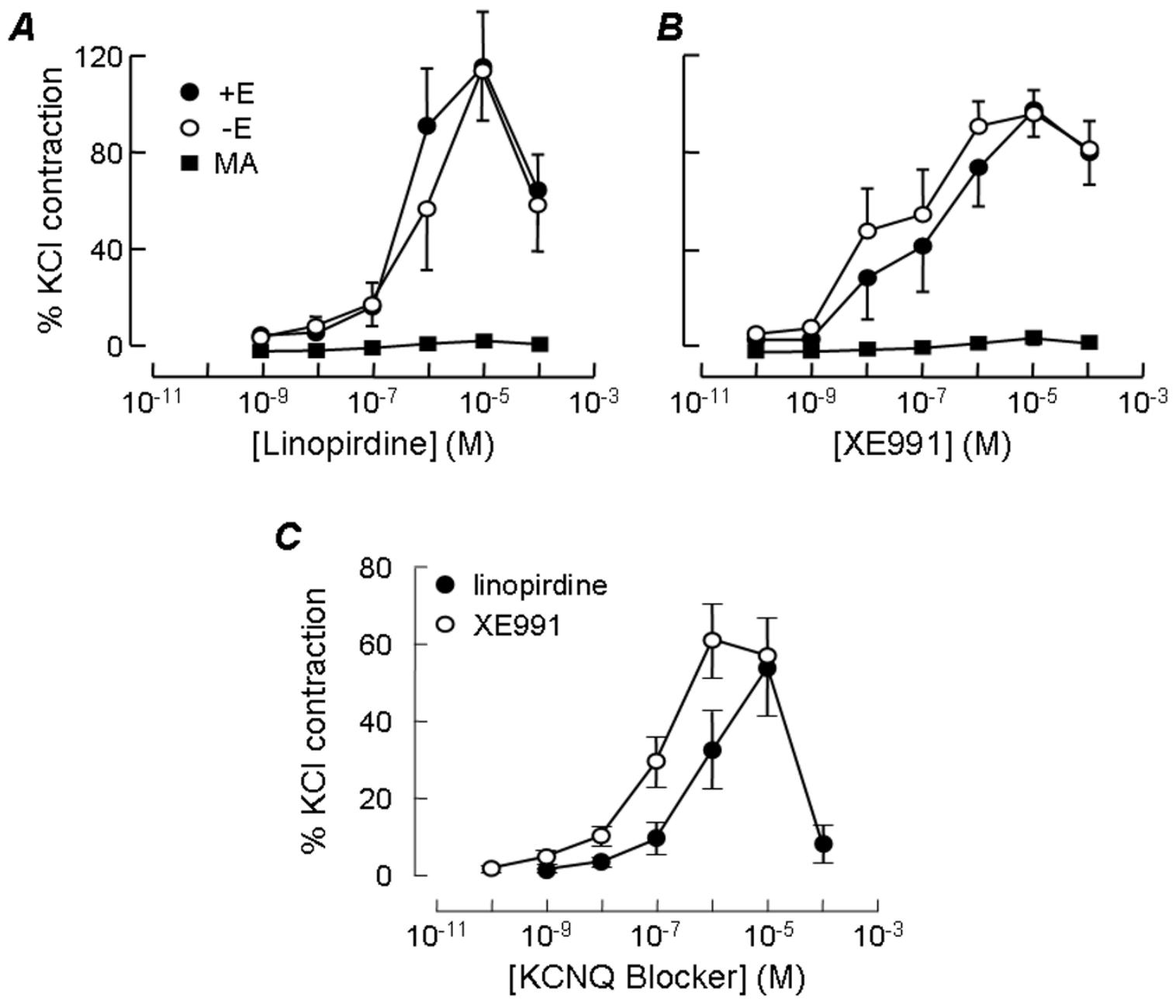

\section{Figure 2}

Concentration-response curves for pulmonary artery constriction by KCNQ channel blockers. Concentration dependence of contraction induced by linopirdine $(A)$ or XE99I $(B)$ in rat intrapulmonary arteries that were intact $(+E)$ or denuded of endothelium (-E). Plots also show the mean responses of rat mesenteric arteries (MA) at the same drug concentrations. Each point represents the mean \pm SEM of 5-6 experiments. $C$. Concentration dependence of contraction induced by linopirdine $(n=9)$ or XE99I $(n=I I)$ in intact mouse intrapulmonary arteries. Responses were measured in each vessel as a percentage of the contractile response to $50 \mathrm{mM} \mathrm{KCl}$.

responses to the KCNQ channel blockers were tested in a similar way. Vessels were challenged once with linopirdine $(10 \mu \mathrm{M})$ or XE991 $(1 \mu \mathrm{M})$ under control conditions and once in the presence of each of these drugs.

The dihydrochloride salts of linopirdine and XE991 were purchased from Tocris Bioscience. Stock solutions (10 $\mathrm{mM}$ ) prepared in distilled water were stored as frozen aliquots and diluted to the final bath concentration in PSS. A few experiments used linopirdine from Sigma, stored as a $10 \mathrm{mM}$ stock dissolved in dimethylsulphoxide. Nifedipine, levcromakalim, phentolamine hydrochloride, phenylephrine hydrochloride, acetylcholine chloride and ethylene glycol-bis(2-aminoethylether)-N,N,N',N'- tetraacetic acid (EGTA) were all from Sigma. Data are expressed as means \pm S.E.M of $\mathrm{n}$ animals and compared using paired or unpaired Student's t test, as appropriate. Differences were considered statistically significant when $\mathrm{p}<0.05$.

\section{Results}

Pulmonary vasoconstriction by KCNQ channel blockers

When applied to rat intrapulmonary arteries both linopirdine and XE991 produced concentration-dependent contraction with an amplitude that was often as large as the contraction induced by $50 \mathrm{mM} \mathrm{K}^{+}$(Fig 1A,B). Figure 2A shows the concentration-response curve for linopirdine, constructed from the mean data obtained from 6 vessels. 

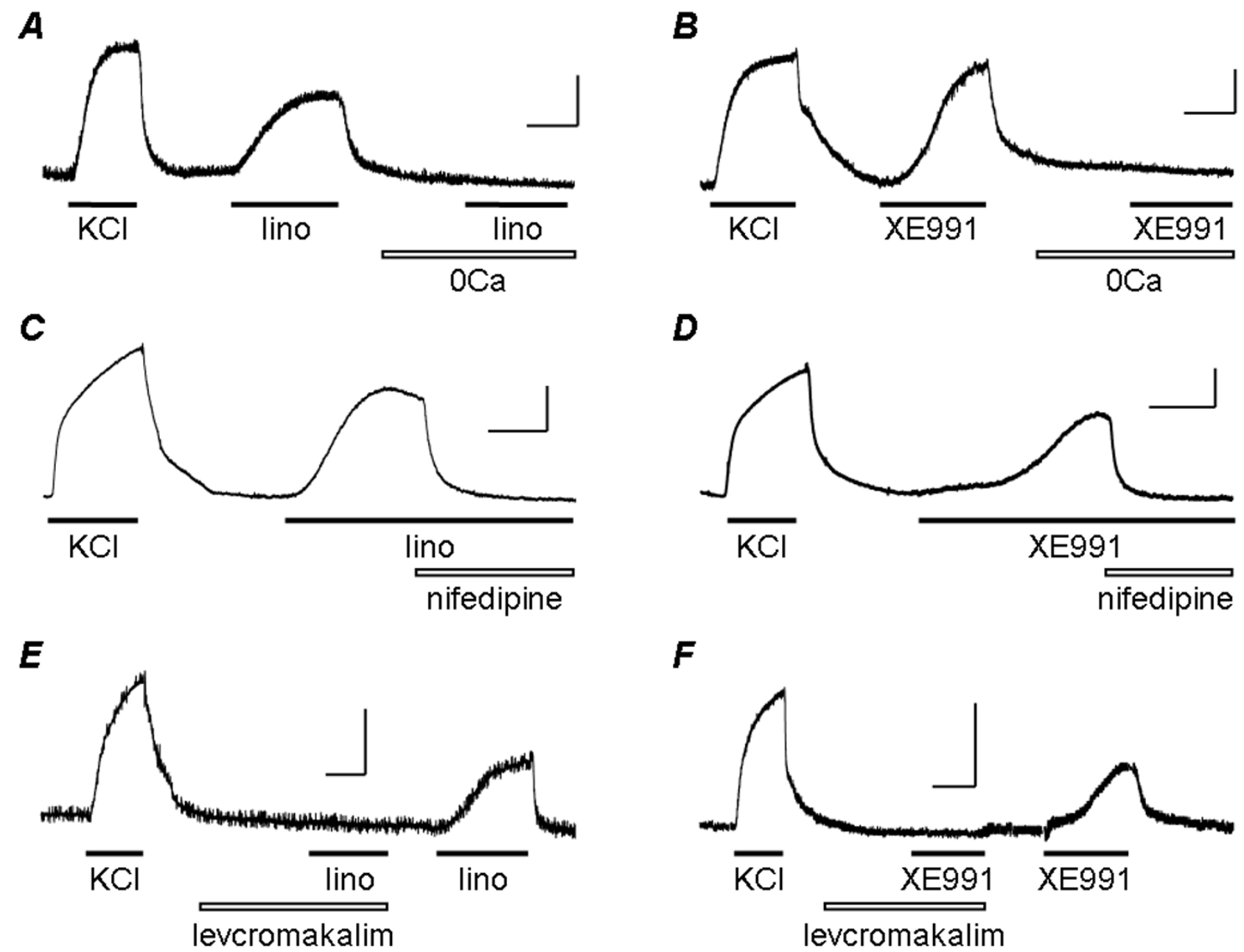

\section{Figure 4}

Mechanism of contraction induced by KCNQ channel blockers. Original records show contractile responses of rat intrapulmonary artery to $50 \mathrm{mM} \mathrm{KCl}$, followed by $10 \mu \mathrm{M}$ linopirdine $(A, C, E)$ or I $\mu \mathrm{M} X \mathrm{X} 99 \mathrm{I}(B, D, F)$ under control conditions and in the presence of $\mathrm{Ca}^{2+}$-free $(0 \mathrm{Ca})$ bathing solution $(A, B), \mathrm{I} \mu \mathrm{M}$ nifedipine $(C, D)$ or $10 \mu M$ levcromakalim $(E, F)$.

Each increase in drug concentration was made after contraction had appeared to reach a steady level and tension was measured as the level reached immediately before addition of the higher concentration. It can be seen that the drug was maximally effective at $10 \mu \mathrm{M}$. When the data in Fig 1A was pooled with experiments in which vessels were challenged with a single application of $10 \mu \mathrm{M}$ linopirdine, the mean contraction at this concentration had an amplitude $85 \pm 12 \%(n=21)$ of that induced by $50 \mathrm{mM} \mathrm{K}^{+}$. No further contraction was observed at higher linopirdine concentrations. In fact, upon addition of 100 $\mu \mathrm{M}$ linopirdine, vessels displayed relaxation (Fig. 1A) with tension returning around 30\% towards the baseline (Fig. 2A). This precluded fitting the Hill equation to obtain the concentration producing $50 \%$ of the maximum response $\left(\mathrm{EC}_{50}\right)$, which was instead estimated by interpolation of the concentration-response curves for each vessel tested. This gave $\mathrm{EC}_{50}=1.3 \pm 0.5 \mu \mathrm{M}(\mathrm{n}=6)$ for linopirdine. XE991 was more potent than linopirdine, often producing substantial contractions below $10 \mathrm{nM}$ (Fig. 1B). The $\mathrm{EC}_{50}$, estimated as above, was $0.4 \pm 0.3 \mu \mathrm{M}$ $(\mathrm{n}=6)$. The maximal response was usually observed at 1 or $10 \mu \mathrm{M} \mathrm{XE991,} \mathrm{where} \mathrm{it} \mathrm{was} \mathrm{nearly} \mathrm{as} \mathrm{large} \mathrm{as} \mathrm{the} \mathrm{con-}$ tractile response to $50 \mathrm{mM} \mathrm{K}^{+}$(Fig $\left.2 \mathrm{~B}\right)$. The mean amplitude of all contractions induced by $1 \mu \mathrm{M}$ XE991 was $79 \pm$ $8 \%(\mathrm{n}=21)$ of the response to $\mathrm{K}^{+}$. This was not significantly different from the maximum response to linopirdine. As seen with linopirdine, during cumulative applications of XE991 relaxation was sometimes observed at high concentrations $(10 \mu \mathrm{M})$. The time course of the contractile responses to linopirdine and XE991 were somewhat variable. Most figures show traces in which the contractions developed over $15 \mathrm{~min}$ or so and recovered fully within around $30 \mathrm{~min}$. In many tissues however, 
A

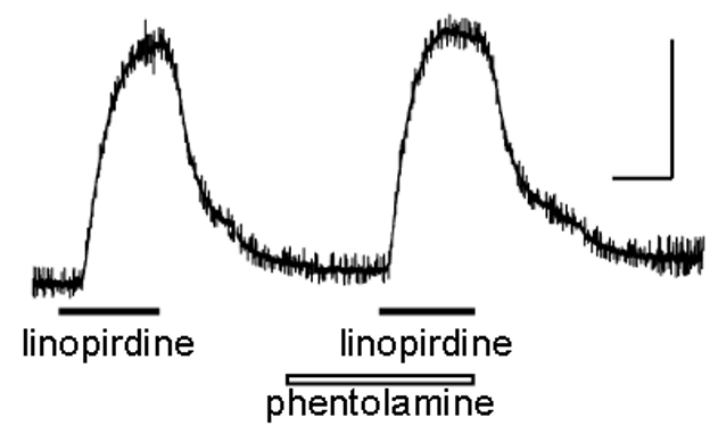

c

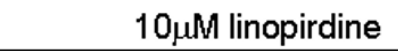

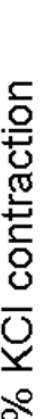

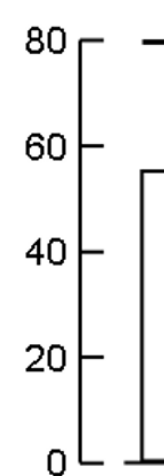

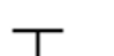
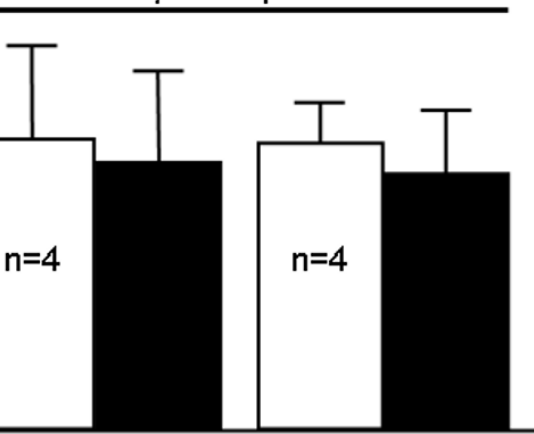

C

Phen

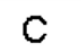

$$
\alpha, \beta \text {-mATP }
$$

B

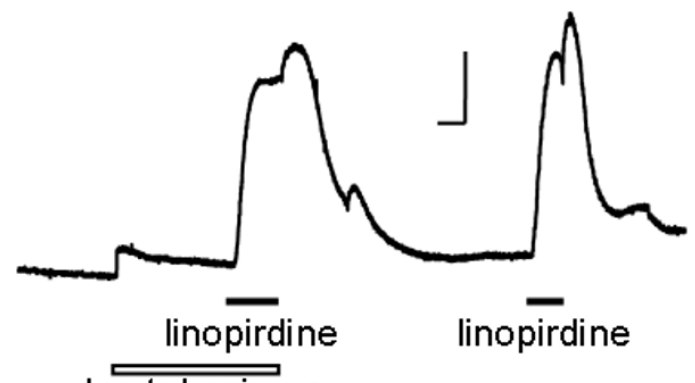

phentolamine +

$\alpha, \beta-$ methylene ATP

\section{Figure 3}

Contraction is independent of nerve released noradrenaline or ATP. A. Original record showing contraction of rat intrapulmonary artery to $10 \mu \mathrm{M}$ linopirdine before and then during exposure to $10 \mu \mathrm{M}$ phentolamine. $B$. Original record showing contraction of rat intrapulmonary artery to $10 \mu \mathrm{M}$ linopirdine after exposing the tissue to $10 \mu \mathrm{M}$ phentolamine plus I $\mu \mathrm{M}$ $\alpha, \beta$-methylene ATP for 30 min and then again following washout of phentolamine and $\alpha, \beta$-methylene ATP. Calibration bars are I $\mathrm{mN}$ (vertical) and $10 \mathrm{~min}$ (horizontal). Drug applications are indicated. B. Histogram showing the mean amplitudes of contractile responses to $10 \mu \mathrm{M}$ linopirdine and I $\mu \mathrm{M}$ XE99I under control conditions $(\mathrm{C})$ and following 30 min exposure to 10 $\mu \mathrm{M}$ phentolamine (Phen) or Phen plus I $\mu \mathrm{M} \alpha, \beta$-methylene ATP $(\alpha, \beta-\mathrm{mATP})$. Responses were measured in each vessel as a percentage of the contractile response to $50 \mathrm{mM} \mathrm{KCl}$. The number of observations is shown next to each bar.

contraction took up to 30 min to develop, sometimes beginning after a substantial delay (e.g. Fig. 4D), and complete recovery often took over an hour after washing. This variable time course means that although, during experiments, contraction appeared to reach a steady level at each concentration, it may not always have developed fully at low concentrations (e.g. Fig. 1A,B,D), which could cause the $\mathrm{EC}_{50}$ values to be overestimated.

Both linopirdine and XE991 had similar effects on mouse intrapulmonary arteries (Fig. 1C,D). The concentration dependence of their actions on mouse vessels is shown in
Fig. 2C. The EC50 for linopirdine, estimated as above, was $0.6 \pm 0.2 \mu \mathrm{M}(\mathrm{n}=9)$. The EC50 for XE991 was $0.12 \pm 0.03$ $\mu \mathrm{M}(\mathrm{n}=11)$, making it significantly more potent than linopirdine $(\mathrm{p}<0.05)$. The drugs were maximally effective at the same concentrations observed in rat arteries and the maximal contractions of mouse pulmonary artery to the two drugs were not significantly different. Linopirdine (10 $\mu \mathrm{M})$ induced a contraction amounting to $54 \pm 12 \%(\mathrm{n}=$ 9) of the response to $50 \mathrm{mM} \mathrm{K}+$ while the contraction induced by $1 \mu \mathrm{M}$ XE991 was $61 \pm 10 \%(\mathrm{n}=11)$ of the response to $\mathrm{K}+$. Also as observed in rat, during cumulative applications a relaxation response to both drugs became 


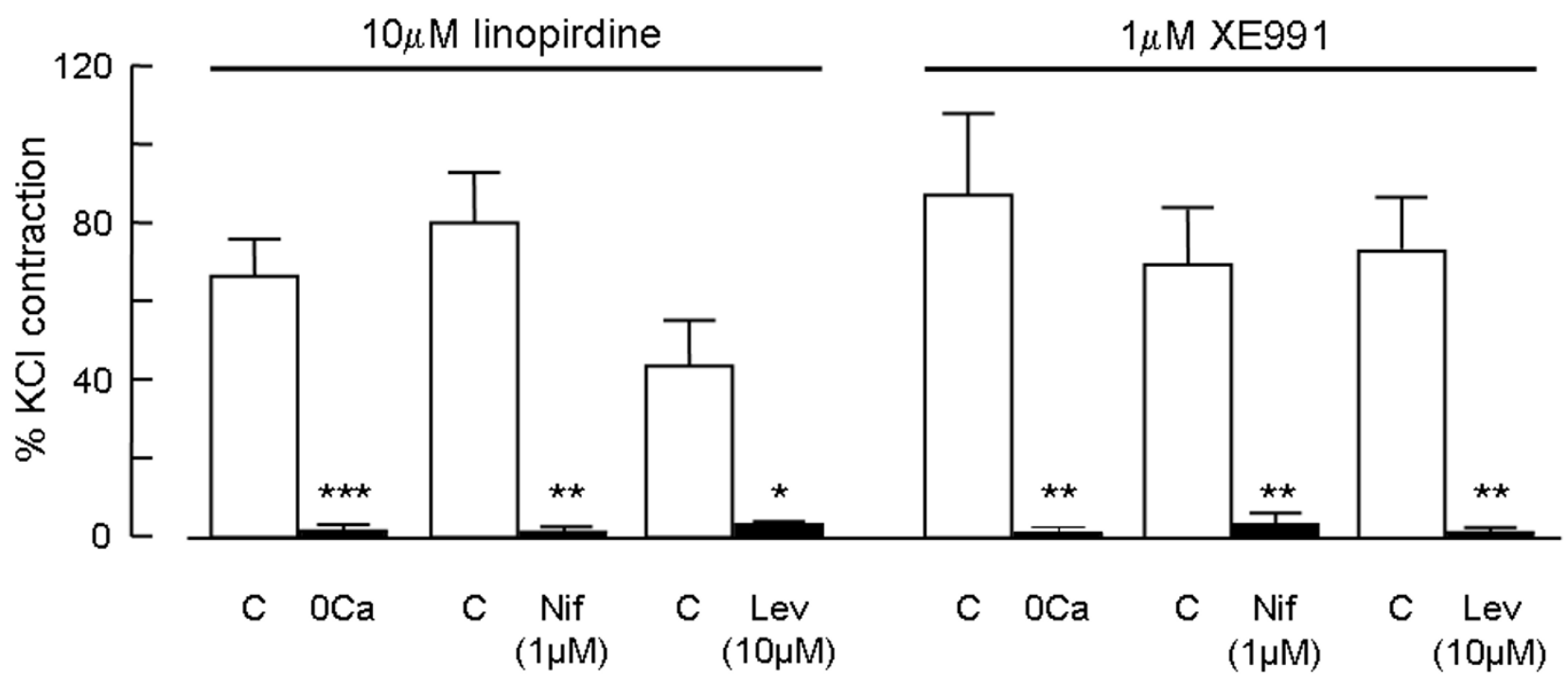

\section{Figure 5}

Contraction requires voltage-dependent $\mathbf{C a}^{2+}$ influx. Histogram comparing the mean amplitudes of contractile responses to $10 \mu \mathrm{M}$ linopirdine or I $\mu \mathrm{M}$ XE99I under control conditions and in the presence of $\mathrm{Ca}^{2+}$-free $(0 \mathrm{Ca})$ bathing solution ( $\mathrm{n}=6$ for both drugs), I $\mu$ M nifedipine (Nif; $\mathrm{n}=5$ for both drugs) or $10 \mu \mathrm{M}$ levcromakalim (Lev; $\mathrm{n}=4$ for linopirdine; $\mathrm{n}=$ 5 for XE99I). Responses were measured in each vessel as a percentage of the contractile response to $50 \mathrm{mM} \mathrm{KCl}$. *** $<$ 0.001 , ** $*_{p}<0.01$, * $*_{p}<0.05$ compared with paired control.

apparent at the highest concentrations tested (Fig. 1C,D, Fig. 2C.

In contrast to the effects of linopirdine and XE991 on pulmonary arteries, neither drug had a significant effect on mesenteric arteries from the same animals. Original traces show little effect on rat (Fig. 1E) or mouse (Fig. 1F) mesenteric arteries, despite them contracting strongly in response to the application of $50 \mathrm{mM} \mathrm{K}^{+}$. The lack of effect is clear in the concentration-effect curves shown for rat in Fig. 2A,B, where responses in mesenteric artery are directly compared with intrapulmonary arteries of similar size.

\section{KCNQ channel blockers act directly on pulmonary artery smooth muscle}

Both linopirdine and XE991 continued to constrict pulmonary arteries after endothelial function was blocked, by removing endothelium from the vessel lumen and inhibiting the release of nitric oxide and prostacyclin. In fact the concentration-response curves to linopirdine (Fig. 2A) and XE991 (Fig. 2B) were essentially unaltered in the absence of endothelium, indicating that the presence of endothelium is not needed for the drugs to cause contraction.
Linopirdine is known to evoke the release of neurotransmitters by inhibiting neuronal $\mathrm{K}^{+}$channels [14]. It is therefore possible that KCNQ channel blockers constrict pulmonary arteries by releasing neurotransmitters from nerve terminals in the vessel wall, which in turn activate the contractile response. The pulmonary circulation is innervated by sympathetic nerves, which release noradrenaline to activate contraction via $\alpha_{1}$-adrenoceptors located on the smooth muscle. To investigate the potential involvement of noradrenaline in the response to the KCNQ channel blockers, we determined the ability of phentolamine, an $\alpha$-adrenoceptor antagonist, to prevent the constrictor response. As shown in Fig. 3, phentolamine $(10 \mu \mathrm{M})$, at a concentration more than sufficient to inhibit the actions of nerve released noradrenaline, had no significant effect on the contractions induced by $10 \mu \mathrm{M}$ linopirdine or $1 \mu \mathrm{M}$ XE991. In rat small intrapulmonary arteries the main transmitter evoking excitation and contraction is ATP, acting on P2 receptors [17]. We investigated the potential role of this transmitter by blocking its action with $\alpha, \beta$-methylene ATP $(1 \mu \mathrm{M})$, applied in the presence of phentolamine $(10 \mu \mathrm{M})$. At this concentration $\alpha, \beta$-methylene ATP depolarises the membrane and causes contraction, followed by repolarisation and relaxation 
over the next 15-30 min as P2X1 receptors become desensitised $[17,18]$. At this time, vessels fail to respond to the application of ATP [18]. Following $30 \mathrm{~min}$ exposure to 1 $\mu \mathrm{M} \alpha, \beta$-methylene ATP, linopirdine $(10 \mu \mathrm{M})$ and XE991 $(1 \mu \mathrm{M})$ continued to induce constriction of rat pulmonary artery (Fig. 3C). The amplitudes of the contractions induced by linopirdine and XE991 were not significantly different when the drugs were applied under control conditions or after $30 \mathrm{~min}$ exposure to $\alpha, \beta$-methylene ATP and phentolamine (Fig. 3D).

\section{Pulmonary artery constriction requires voltage-dependent $\mathrm{Ca2}+$ influx}

To determine how much of the contraction induced by KCNQ channel blockers required $\mathrm{Ca}^{2+}$ influx from the extracellular space, we investigated the effect on the response of removing extracellular $\mathrm{Ca}^{2+}$. When vessels were exposed to $\mathrm{Ca}^{2+}$-free PSS for $20 \mathrm{~min}$ before applying $10 \mu \mathrm{M}$ linopirdine (Fig. 4A) or $1 \mu \mathrm{M} \mathrm{XE991} \mathrm{(Fig.} \mathrm{4B)} \mathrm{the}$ drugs had essentially no effect on tension, although they produced contraction in the same vessels exposed to normal PSS, whether applied before the test in $\mathrm{Ca}^{2+}$-free solution or after the normal $\mathrm{Ca}^{2+}$ concentration had been restored. Fig. 5 summarises the mean results and shows that in the absence of extracellular $\mathrm{Ca}^{2+}$ the contractile responses to linopirdine and XE991 were essentially abolished.

Several distinct pathways could potentially mediate $\mathrm{Ca}^{2+}$ influx underlying the contraction of pulmonary artery smooth muscle. To determine the contribution of voltagegated, L-type $\mathrm{Ca}^{2+}$ channels, we investigated the effects of the selective $\mathrm{Ca}^{2+}$ channel antagonist, nifedipine, on contractions induced by the KCNQ channel blockers. When nifedipine $(1 \mu \mathrm{M})$ was applied to vessels pre-constricted with $10 \mu \mathrm{M}$ linopirdine (Fig. 4C) or $1 \mu \mathrm{M}$ XE991 (Fig. 4D) the tension rapidly declined to the baseline. In addition, when vessels were pre-exposed to nifedipine $(1 \mu \mathrm{M})$ for $10 \mathrm{~min}$, linopirdine and XE991 failed to produce contraction (not shown). Comparison of the mean amplitudes of contractions evoked by linopirdine or XE991 in the absence and presence of nifedipine shows that nifedipine essentially abolished the contractile responses to both drugs (Fig. 5).

If the contractions induced by linopirdine and XE991 depend on membrane depolarisation and activation of $\mathrm{Ca}^{2+}$ influx through voltage-gated $\mathrm{Ca}^{2+}$ channels, then they should be inhibited under conditions that promote hyperpolarisation and oppose the depolarising action of the drugs. To determine if this was the case, we examined how the contractions were affected by the $\mathrm{K}^{+}$channel opening drug, levcromakalim. This drug activates $\mathrm{K}_{\mathrm{ATP}}$ channels and causes hyperpolarisation of pulmonary artery smooth muscle cells [19]. At $10 \mu \mathrm{M}$, levcromakalim hyperpolarises pulmonary artery smooth muscle cells by around $15 \mathrm{mV}$ [20], taking the membrane potential well away from the voltage threshold for activating L-type $\mathrm{Ca}^{2+}$ channels. When applied in the presence of $10 \mu \mathrm{M}$ levcromakalim neither $10 \mu \mathrm{M}$ linopirdine (Fig. 4E) nor $1 \mu \mathrm{M}$ XE991 (Fig. 4F) caused contraction in vessels that responded well to both drugs after levcromakalim was washed from the tissue with PSS for around $10 \mathrm{~min}$. Comparison of the mean amplitudes of contractions evoked by linopirdine or XE991 in the absence and presence of levcromakalim shows that the contractile responses to both drugs were essentially abolished (Fig. 5).

\section{Discussion}

The KCNQ channel blockers, linopirdine and XE991, were both found to act as potent constrictors of rat and mouse pulmonary arteries. Linopirdine constricted arteries from both species with an $\mathrm{EC}_{50}$ of around $1 \mu \mathrm{M}$, which is similar to the $2-3 \mu \mathrm{M}$ concentrations found for $50 \%$ inhibition $\left(\mathrm{IC}_{50}\right)$ of native $\mathrm{M}$ current in hippocampal neurons and sympathetic ganglia $[15,21]$. It is also close to the $\mathrm{IC}_{50}$ values reported for inhibition of homomeric KCNQ1 $(8.9 \mu \mathrm{M}), \mathrm{KCNQ} 2(\sim 4 \mu \mathrm{M})$ and KCNQ3 $(4.8 \mu \mathrm{M})$ channels and heteromeric KCNQ2/3 channels (3.5-10 $\mu \mathrm{M})$ and at least 10 -fold lower than reported for other homomeric or heteromeric KCNQ channels [2]. XE991 generally has a 10-fold lower $\mathrm{IC}_{50}$ for KCNQ channels than linopirdine, although the relative potency of the drugs varies among different KCNQ subunits and subunit combinations [2]. It blocks KCNQ1 and KCNQ2 homomers, as well as KCNQ2/3 heteromers, with an $\mathrm{IC}_{50}$ of $0.6-$ $0.8 \mu \mathrm{M}$, which is similar to the $\mathrm{EC}_{50}$ estimated for pulmonary artery constriction. Our $\mathrm{EC}_{50}$ measurements may have been affected by the presence of a relaxant action at the top end of the concentration-effect curve, leading to a possible underestimate. Nevertheless, the potencies found in this study are among the highest reported for linopirdine or XE991 actions in any tissue, consistent with the idea that they produced pulmonary vasoconstriction through an interaction with KCNQ channels.

The pulmonary vasoconstrictor effects of linopirdine and XE991 appear to be mediated by a direct action on the smooth muscle cells of the vessel wall. They do not require the presence of an intact endothelium, because removing the endothelium did not alter the contractile response to either drug. Since KCNQ channel blockers are known to stimulate neurotransmitter release [14], it was important to check the potential involvement of neuronal KCNQ channels in the vasoconstrictor response, the blockade of which might result in transmitters being released from nerve endings in the artery wall. Neither inhibition of $\alpha_{1}$-adrenoceptors with phentolamine, nor desensitization of $\mathrm{P} 2 \mathrm{X}$ receptors with $\alpha, \beta$-methylene ATP, had any effect on the pulmonary vasoconstrictor 
responses to linopirdine or XE99l. Since these are the main transmitters mediating electrical and contractile responses to nerve stimulation in rat intrapulmonary arteries $[17,22]$, it is highly unlikely that neurotransmitters released in the vessel wall play a significant role in mediating the pulmonary vasoconstrictor effect of the KCNQ channel blockers.

The pulmonary vasoconstriction induced by linopirdine or XE991 was abolished in $\mathrm{Ca}^{2+}$-free medium. This indicates that the contraction was dependent upon $\mathrm{Ca}^{2+}$ influx from the extracellular space into the smooth muscle cells and did not involve $\mathrm{Ca}^{2+}$ release from intracellular stores. Furthermore, abolition of the constrictor responses in the presence of nifedipine indicates that $\mathrm{Ca}^{2+}$ entered the cells through voltage-gated, $\mathrm{L}$-type $\mathrm{Ca}^{2+}$ channels. This is what would be expected if the KCNQ channel blockers were producing constriction by blocking resting $\mathrm{K}^{+}$channels and inducing depolarisation of the smooth muscle cell membrane. That this is the mechanism underlying the vasoconstrictor responses to linopirdine and XE991 is further supported by the ability of levcromakalim, a $\mathrm{K}_{\text {ATP }}$ channel opener, to abolish the responses. At the concentration used, levcromakalim hyperpolarizes pulmonary artery smooth muscle cells close to the $\mathrm{K}^{+}$equilibrium potential $[19,20]$. This is demonstrated by its lack of effect on the tension developed by vessels exposed to a high extracellular $\mathrm{K}^{+}$concentration $[20,23]$, where vessels contract due to membrane depolarization and $\mathrm{Ca}^{2+}$ influx. The pronounced effect of levcromakalim on the responses to linopirdine and XE991 contrasts with only partial inhibition of the constrictor responses to a number of receptor agonists, where it blocks only the component of contraction that results from voltage-dependent $\mathrm{Ca}^{2+}$ influx $[20,23]$. This implies that the constrictor responses to linopirdine and XE991 are strongly dependent on the membrane potential and/or $\mathrm{K}^{+}$flux, and voltage-gated $\mathrm{Ca}^{2+}$ influx.

Linopirdine has generally been found to be well tolerated in humans, with few adverse effects. Pulmonary vasoconstriction is, however, a potentially serious side effect that might not be picked up by routine examinations. Since linopirdine and XE991 constricted pulmonary arteries while having no effect on mesenteric arteries from the same species, they are likely to elevate pulmonary arterial pressure without a change in systemic blood pressure. Consistent with this, linopirdine had no effect on blood pressure or pulse rate in human volunteers [24]. Possible effects on the pulmonary circulation have not been investigated in vivo. The lack of effect on mesenteric arteries suggests that the vasoconstrictor action of KCNQ channel blockers may be selective for the pulmonary circulation. A recent report indicates that linopirdine $(50 \mu \mathrm{M})$ and XE991 $(10 \mu \mathrm{M})$ can also modulate the spontaneous con- tractions of portal vein [13], but these effects were observed at higher concentrations than required to constrict pulmonary artery. Further studies are required to determine if other blood vessels can be affected by these drugs.

\section{Conclusion}

The KCNQ $\mathrm{K}^{+}$channel blocking drugs, linopirdine and XE991, are potent and powerful constrictors of pulmonary arteries. This is a potentially serious side effect of the drugs and should be considered as KCNQ blockers are developed for clinical use. The lack of a similar response in mesenteric arteries suggests that this action may be selective for the pulmonary circulation. All of the data point to an action on the smooth muscle cells of pulmonary arteries, involving $\mathrm{K}^{+}$-channel blockade, membrane depolarisation and $\mathrm{Ca}^{2+}$ influx as the mechanism underlying the response. This strongly suggests that KCNQ channels play a functional role in pulmonary artery smooth muscle, most likely contributing to the resting $\mathrm{K}^{+}$conductance and resting potential. If so, then drugs like retigabine, which activate KCNQ channels [2], could be effective and selective dilators of pulmonary arteries and may prove useful in the treatment of pulmonary hypertension.

\section{Competing interests}

The author(s) declare that they have no competing interests.

\section{Authors' contributions}

SJ carried out most of the experimental work, contributed to the design and coordination of the study and helped to draft the manuscript. PB carried out some of the experimental work. AMG conceived of the study, participated in its design and coordination and drafted the manuscript. All authors read and approved the final manuscript.

\section{Acknowledgements}

The work was supported by the Biotechnology and Biological Sciences Research Council (A.G.)

\section{References}

I. Jentsch TJ: Neuronal KCNQ potassium channels: physiology and role in disease. Nature Reviews 2000, I:2I-30.

2. Robbins J: KCNQ potassium channels: physiology, pathophysiology, and pharmacology. Pharmacol Ther 200I, 90:I-I9.

3. Brown DA: M currents. In Ion Channels Volume I. Edited by: Narahashi T. New York: Plenum Press; 1988:55-99.

4. Wang H-S, Pan Z, Shi W, Brown BS, Wymore RS, Cohen IS, Dixon JE, McKinnon D: KCNQ2 and KCNQ3 potassium channel subunits: molecular correlates of the M-channel. Science 1998, 282: 1890-1893.

5. Tinel N, Diochot S, Lauritzen I, Barhanin J, Lazdunski M, Borsotto M: M-type KCNQ2-KCNQ3 potassium channels are modulated by the KCNE2 subunit. FEBS Lett 2000, 480:137-I4I.

6. Lerche C, Scherer CR, Seebohm G, Derst C, Wei AD, Busch AE, Steinmeyer K: Molecular cloning and functional expression of KCNQ5, a potassium channel subunit that may contribute to neuronal M-current diversity. I Biol Chem 2000, 275:22395-22400. 
7. Schroeder BC, Hechenberger M, Weinreich F, Kubisch $C$, Jentsch T]: KCNQ5, a novel potassium channel broadly expressed in brain, mediates M-type currents. J Biol Chem 2000, 275:24089-24095.

8. Evans AM, Osipenko ON, Gurney AM: Properties of a novel $\mathbf{K}^{+}$ current that is active at resting potential in rabbit pulmonary artery smooth muscle cells. J Physiol 1996, 496:407-420.

9. Gurney AM, Osipenko ON, MacMillan D, McFarlane KM, Tate RJ, Kempsill FE: Two-pore domain $\mathrm{K}$ channel, TASK-I, in pulmonary artery smooth muscle cells. Circ Res 2003, 93:957-964.

10. Yang W-P, Levesque PC, Little WA, Conder ML, Shalaby FY, Blanar MA: KvLQTI, a voltage-gated potassium channel responsible for human cardiac arrhythmias. Proc Natl Acad Sci USA 1997, 94:4017-4021.

II. Teng S, Ma L, Zhen Y, Lin C, Bahring R, Vardanyan V, Pongs O, Hui R: Novel gene hKCNE4 slows the activation of the KCNQI channel. Biochem Biophys Res Commun 2003, 303:808-8I3.

12. Ohya S, Sergeant GP, Greenwood IA, Horowitz B: Molecular variants of KCNQ channels expressed in murine portal vein myocytes: a role in delayed rectifier current. Circ Res 2003 , 92:1016-1023.

13. Yeung SY, Greenwood IA: Electrophysiological and functional effects of the KCNQ channel blocker XE99 I on murine portal vein smooth muscle cells. BrJ Pharmacol 2005, I 46:585-595.

14. Nickolson VJ, Tam SW, Meyers MJ, Cook L: DuP 996(3,3-bis(4pyridinylmethyl)-I-phenylindolin-2-one) enhances the stimulus-induced release of acetylcholine from rat brain in vitro and in vivo. Drug Dev Res 1990, 19:285-300.

15. Lamas JA, Selyanko AA, Brown DA: Effects of a cognitionenhancer, linopirdine (DuP 996), on M-type potassium currents $\left(\mathrm{IK}_{\mathrm{M}}\right)$ and some other voltage- and ligand-gated membrane currents in rat sympathetic neurons. Eur J Neurosci 1997, 9:605-616

16. Wang HS, Brown BS, McKinnon D, Cohen IS: Molecular basis for differential sensitivity of $K C N Q$ and $I_{K s}$ channels to the cognitive enhancer XE99I. Mol Pharmacol 2000, 57:|2| $8-1223$.

17. Inoue T, Kannan MS: Nonadrenergic and noncholinergic excitatory neurotransmission in rat intrapulmonary artery. $\mathrm{Am} J$ Physiol I988, 254:HII42-HII48.

18. Chootip K, Ness KF, Wang Y, Gurney AM, Kennedy C: Regional variation in $\mathbf{P 2}$ receptor expression in the rat pulmonary arterial circulation. Br J Pharmacol 2002, 137:637-646.

19. Clapp LH, Gurney AM: ATP-sensitive $\mathbf{K}^{+}$channels regulate resting potential of pulmonary arterial smooth muscle cells. $\mathrm{Am}$ Physiol 1992, 262: $\mathrm{H} 916-\mathrm{H} 920$

20. Clapp LH, Davey R, Gurney AM: ATP-sensitive $\mathbf{K}^{+}$channels mediate vasodilation produced by lemakalim in rabbit pulmonary artery. Am J Physiol 1993, 264:HI907-HI9I5.

21. Schnee ME, Brown BS: Selectivity of linopirdine (DuP996), a neurotransmitter release enhancer, in blocking voltagedependent and calcium-activated potassium currents in hippocampal neurons. J Pharmacol Exp Ther 1998, 286:709-7I7.

22. Barnes PJ, Liu SF: Regulation of pulmonary vascular tone. Pharmacol Rev 1995, 47:87-I3I.

23. Savineau JP, Marthan R: Effect of cromakalim on KCLnoradrenaline- and angiotensin II-induced contractions in the rat pulmonary artery. Pulm Pharmacol 1993, 6:4I-48.

24. Pieniaszek HL, Fiske WD, Saxton TD, Kim YS, Garner DM, Xilinas M, Martz R: Single-dose pharmacokinetics, safety, and tolerance of linopirdine (Du 996) in healthy young adults and elderly volunteers. J Clin Pharmacol 1995, 35:22-30.
Publish with Biomed Central and every scientist can read your work free of charge

"BioMed Central will be the most significant development for disseminating the results of biomedical research in our lifetime. "

Sir Paul Nurse, Cancer Research UK

Your research papers will be:

- available free of charge to the entire biomedical community

- peer reviewed and published immediately upon acceptance

- cited in PubMed and archived on PubMed Central

- yours - you keep the copyright

Submit your manuscript here:

http://www.biomedcentral.com/info/publishing_adv.asp
BioMedcentral 